\title{
Moral Relativism, Metalinguistic Negotiation, and the Epistemic Significance of Disagreement
}

\author{
Katharina Anna Sodoma ${ }^{1,2}$ (D)
}

Received: 25 March 2020 / Accepted: 26 April 2021 / Published online: 26 May 2021

(C) The Author(s) 2021

\begin{abstract}
Although moral relativists often appeal to cases of apparent moral disagreement between members of different communities to motivate their view, accounting for these exchanges as evincing genuine disagreements constitutes a challenge to the coherence of moral relativism. While many moral relativists acknowledge this problem, attempts to solve it so far have been wanting. In response, moral relativists either give up the claim that there can be moral disagreement between members of different communities or end up with a view on which these disagreements have no "epistemic significance" because they are always faultless. This paper introduces an alternative strategy: accounting for disagreement in terms of "metalinguistic negotiation". It argues that this strategy constitutes a better solution to the challenge disagreement poses for moral relativists because it leads to a nuanced understanding of the epistemic significance of moral disagreement between members of different communities. The upshot is a novel account of disagreement for moral relativists that has consequences for how moral relativism should be understood.
\end{abstract}

\section{Introduction}

Imagine two people disagreeing about whether eating animals is morally wrong. Now, assume that they live their lives in very different contexts, shaped by different practices that imply different moral norms. Perhaps these distinct sets of moral norms are connected to different religions or even to different conceptions of humans' relationship to nature. Suppose that one day they meet and-perhaps with the help of a translator-become aware of their conflict. They engage in a dispute, but the differences in their outlooks make it difficult to reach a shared understanding and so their disagreement remains unresolved. This is the kind of scenario moral

Katharina Anna Sodoma

katharina.anna.sodoma@univie.ac.at; katharina.sodoma@uni-due.de

1 Present Address: Department of Philosophy, University of Duisburg-Essen, Essen, Germany

2 Department of Philosophy, University of Vienna, Vienna, Austria 
relativists often appeal to in order to motivate their view. However, it also seems that disagreements like the one described above have "epistemic significance"; that is, they give us reason to reconsider our views (cf. Carter, 2014). It is often assumed that this is because they indicate that a mistake has been made. But if whenever two people engage in a moral disagreement one of them must be wrong, then it cannot be the case that there are different and conflicting moral systems, each of which determining what is morally required in its own context. Therefore, although moral relativists often appeal to exchanges like the one in the example in order to motivate their view, at the same time, accounting for these exchanges as evincing genuine disagreements constitutes a challenge to the coherence of moral relativism.

In response to this problem, moral relativists have either given up the claim that moral disputes between members of different communities constitute genuine disagreements or argued that these disagreements have no epistemic significance because they are always faultless. These solutions come at a cost. Exchanges like the one about whether eating animals is morally wrong seem to constitute genuine disagreements and-as opposed to e.g. disagreements about whether licorice is tasty-they seem to have epistemic significance. In this paper, I will argue that moral relativists are better off adopting a different strategy, namely, explaining disagreement in terms of what David Plunkett and Tim Sundell call "metalinguistic negotiation" (Plunkett \& Sundell, 2013). The main advantage of this strategy is that it leads to a nuanced understanding of the epistemic significance of moral disagreements between members of different communities.

I will begin by detailing why accounting for moral disagreement between members of different communities constitutes a challenge for moral relativists (Sect. 2). Then, I will discuss three different strategies moral relativists have relied on to meet this challenge: giving up disagreement, arguing for faultless disagreement based on semantic relativism, and explaining disagreement in terms of hybrid-expressivism (Sect. 3). Subsequently, I will introduce an alternative strategy-explaining moral disagreement in terms of metalinguistic negotiation-and argue that it has distinctive advantages (Sect. 4). Finally, I will address an objection to the assumption that moral disagreements between members of different communities are ordinarily taken to have epistemic significance (Sect. 5). I conclude by summarizing my argument and discussing a consequence it has for how moral relativism should be understood.

\section{Disagreement as a Challenge for Moral Relativism}

Because both "relativism" and "disagreement" are contentious notions, to see why disagreement poses a challenge for moral relativists, they need to be clarified. By "moral relativism", I mean any position in metaethics that commits to the following set of claims (cf. Kusch, 2016a, 107f; 2016b, 34f):

What morality permits and requires is relative to a given system of moral norms (Dependence). 
There are, have been or at least could be more than one such moral system (Plurality).

These different moral systems lead to conflicting verdicts (Exclusiveness).

Nevertheless, there is a sense in which they are on a par (Symmetry).

My discussion will be restricted to versions of "moral group relativism"; i.e., to versions of moral relativism that take the relevant system of moral norms to be shared by a community rather than specific to an individual. Influential examples include the views of Gilbert Harman, Carol Rovane, J. David Velleman and David B. Wong (Harman, 1975, 1996; Rovane, 2013; Velleman, 2015; Wong, 2006).

As it stands, the moral relativist's commitment to Symmetry is most in need of elaboration. It is sometimes understood in terms of the claim that all different moral systems are "equally valid", in the sense that any one of them is as good as any other (Equal Validity). However, this is a highly controversial claim. For one, it is implausible that any imaginable moral system would be as good as any other. Moreover, in the context of the moral relativist's other commitments, it remains unclear from what perspective the claim that all systems are "equally valid" can be made, as this claim seems to presuppose the kind of absolute standard the moral relativist denies exists. Therefore, Equal Validity is sometimes taken to be a commitment of relativism by opponents rather than proponents of the view. Because my argument about how moral relativists can explain moral disagreement has consequences for this question, I will return to the question of whether moral relativists are in fact committed to Equal Validity below (Sect. 4).

Because it correlates with their commitment to Dependence, moral relativists often commit to a contextualist semantics for moral judgments. According to semantic contextualism, the content of an utterance is relative to context, so that e.g. if someone utters "Eating animals is morally wrong", according to a contextualist semantics for moral judgments, what they are really expressing is that eating animals is morally wrong according to set of moral standards $S$, where $\mathrm{S}$ is a contextually salient set of moral standards, usually the set of moral standards accepted by the speaker. ${ }^{1}$ While Harman suggests a version of contextualism that postulates additional argument-places for moral expressions (Harman, 1975, 10; cf. 1996, 43), Velleman argues that they are akin to indexicals (Velleman, 2015, 77). Wong and Rovane commit to semantic contextualism in the broad sense that the meaning of moral expressions differs with context (Wong, 2006, 72; Rovane, 2013, 45). ${ }^{2}$

\footnotetext{
1 Not all versions of semantic contextualism for moral judgments relativize the content of an utterance to a set of moral standards. Gunnar Björnsson and Stephen Finlay e.g. defend a version of contextualism for moral judgments as relativized to information (as well as standards) (Björnsson and Finlay, 2010).

2 While the relativization of content to context of utterance offered by semantic contextualism is of special interest to moral relativists, there is no entailment in either direction. Rather, different metaethical positions can be combined with different accounts of the semantics of moral judgments. This is because moral relativism's commitment to Dependence underdetermines semantic options (Silk, 2018, 105) and there might be reasons to allow for semantic context-sensitivity, even if the parameter supplied does not vary (Stojanovic, 2018, 126). An alternative semantic proposal that is of similar interest to moral relativists is semantic relativism. I discuss semantic relativism in Sect. 3.2.
} 
Any definition of moral disagreement needs to address two obstacles. For one, the ordinary notion of a disagreement is ambiguous between an activity-the activity of engaging in a disagreement with someone-and a state-the state of being in disagreement with someone (Cappelen \& Hawthorne, 2009, 60f; MacFarlane, 2014, 119). These two notions can come apart. It is both possible to be in a state of disagreement without ever discovering it and to engage in the activity of disagreeing based on a misunderstanding. Moreover, while it might seem tempting to define moral disagreement in terms of a conflict in beliefs, in the context of metaethics, this would beg the question against noncognitivsm. According to noncognitivists, moral judgments do not express doxastic attitudes such as belief, but rather non-doxastic attitudes such as approval. On this view, moral disagreements cannot consist in a clash of beliefs because moral judgments do not express beliefs in the first place. To address these obstacles, I will adopt the following definition of disagreement as a state of holding conflicting (doxastic or non-doxastic) attitudes (cf. Plunkett \& Sundell, 2013, 11):

$\mathrm{A}$ and $\mathrm{B}$ are in a state of disagreement if and only if A holds attitude $\mathrm{X}$ and $\mathrm{B}$ holds attitude $\mathrm{Y}$ and $\mathrm{X}$ and $\mathrm{Y}$ are "rationally incompatible", in the sense that $\mathrm{A}$ could not adopt $\mathrm{Y}$ (and B could not adopt $\mathrm{X}$ ) without ending up with an incoherent set of attitudes. ${ }^{3}$

Following Plunkett and Sundell, I will refer to any exchange that appears to express a disagreement as a "dispute" (Plunkett \& Sundell, 2013, 6). According to this definition, many disputes might turn out to express no genuine disagreement at all, but instead rest on a misunderstanding. While all disputes that are not based on a misunderstanding will be due to a state of disagreement, not all states of disagreement give rise to a meaningful dispute. Therefore, in addition to identifying a conflict in attitudes, giving a satisfactory account of a given exchange as constituting a genuine disagreement requires identifying a pragmatic point of engaging in the dispute.

The type of disagreement at issue in the debate on moral group relativism is "moral inter-group disagreement", i.e., disagreement about moral questions that occurs between members of different communities (rather than "moral intra-group disagreement", i.e., moral disagreement between members of the same community). The relevant disagreements are "irreducibly" moral, in the sense that they are not due to disagreements about non-moral issues. ${ }^{4}$ Moral relativists often motivate their position by arguing that it presents the best explanation for the existence of

\footnotetext{
3 As John MacFarlane has pointed out, this criterion could turn out to be vacuous in case A and B are already committed to an incoherent set of attitudes (MacFarlane, 2014, 121, n4). However, this potential problem can be circumvented by specifying that A and B would end up with an incoherent set of attitudes solely in virtue of simultaneously holding $\mathrm{X}$ and $\mathrm{Y}$.

4 That the relevant disagreement cannot be reduced to disagreement about non-moral questions need not mean that it is "fundamental" or "deep", i.e., it need not be due to disagreement about fundamental principles (cf. Fogelin, 2005; Kinzel and Kusch, 2018; Lavorerio, 2018). Instead, it might be based e.g. on how shared principles are interpreted, the use of different "thick concepts" or other details of the respective moral systems.
} 
wide-spread moral disputes between members of different communities that remain persistently unresolved. At the same time, however, accounting for the disputes they appeal to in order to motivate their view as constituting genuine disagreements presents a challenge for moral relativists. This challenge is due to the "epistemic significance" of disagreements. Disagreements have epistemic significance because they give us reason to reconsider-if not revise or even reject-our position. They prompt us to see our view in a new light, gather more evidence and engage in a dispute. Because they can thereby lead to an improved state of overall attitudes, disagreements are often taken to have an important epistemological function (cf. e.g. Rovane, 2013, 21).

Suppose that five friends go out to eat at a restaurant and decide to split the bill evenly. They do the math in their heads and one of them becomes confident that their shares are $\$ 43$ each. However, they then learn that their friend has also done the calculation and has become confident that their shares are $\$ 45$ each (Christensen, 2007, 193). In this case, it seems clear that the disagreement gives both disputants reason to reconsider their view and can thereby lead to an improved overall epistemic situation. ${ }^{5}$ However, the epistemic significance of disagreement comes in degrees and differs for different domains. Whereas disagreements about the outcome of a calculation ought to prompt us to reconsider our views, other disagreements, such as e.g. about whether licorice is tasty, need not do so. While the epistemic significance of moral disagreements might not always be as high as that of disagreements about the outcome of a calculation-especially when it occurs between members of different communities-it seems to at least be higher than that of disagreements about taste. ${ }^{6}$

It is often assumed that disagreements have epistemic significance because they show us that something has gone wrong in the sense that at least one of the disputants (but possibly both) must be mistaken. While the assumption that disagreement always indicates that a mistake has been made is stronger than the claim that disagreement has epistemic significance, it is difficult to see why disagreement in an area of discourse would give us reason to reconsider our views if it is always faultless. Therefore, the claim that disagreement has epistemic significance plausibly requires that disagreement indicates that it is at least possible that a mistake has been made. An argument that supports the view that disagreement always indicates

\footnotetext{
5 While the question of how exactly one ought to react to a disagreement in case the other disputant is an "epistemic peer" is discussed in the literature on peer disagreement, the claim that disagreement ought to prompt us to reconsider our attitude is compatible with all views in this debate and also covers cases in which a disputant is not considered an epistemic peer. Registering a disagreement and deciding that one will stick to one's position because the one who disputes it is in no epistemic position to back up their claim is a way of reconsidering and thus at least potentially an apt reaction to the epistemic significance of disagreement.

6 Similar takes on the characteristic of moral disagreements in contrast to disagreements about taste include Crispin Wright's claim that moral disputes are not normally regarded as "disputes of inclination" (Wright, 2012, 449), Delia Belleri's argument that disagreements about taste do not have epistemic significance and therefore do not license disputes (Belleri, 2014, 298), as well as Ragnar Francén's distinction between "unstable" intuitions of disagreement (which we have in cases of disagreements about taste) and "stable" intuitions of disagreement (which we have in cases of moral disagreement) (Francén, 2010, 21f).
} 
that a mistake has been made is Crispin Wright's "simple deduction". This argument takes the form of a reductio ad absurdum based on the premises "A accepts P", "B accepts Not-P" and "A's and B's disagreement involves no mistake" (Wright, 2006, $41 ; 2001,56)$. It relies on the assumption that believing something false amounts to committing a mistake. With this assumption in place, it appears that either $\mathrm{P}$, in which case B would have committed a mistake, or not-P, in which case A would have committed a mistake. ${ }^{7}$

The assumption that disagreement indicates mistake underlies the challenge disagreement poses for moral relativists. If disagreements always indicate that a mistake has been made and moral disputes between members of different communities constitute genuine disagreements, then whenever members of different communities disagree about a moral question, one of them must be wrong. This is incompatible with the moral relativist's commitment to Symmetry, according to which different moral systems are on a par. ${ }^{8}$ However, if moral disputes between members of different communities do not constitute genuine disagreements, then it seems that the disputants' claims do not conflict. This is incompatible with the moral relativist's commitment to Exclusiveness, according to which different moral systems lead to conflicting verdicts. The challenge thus takes the form of a dilemma:

Either moral disputes between members of different communities constitute genuine disagreements, then at least one of the disputants must be mistaken (so Symmetry does not hold) (horn 1); or moral disputes between members of different communities do not constitute genuine disagreements, then their views are compatible (so Exclusiveness does not hold) (horn 2).

The problem lies in that, whichever way one goes, one has to give up one of the elements of moral relativism. But without taking a coherent stance on whether moral disputes between members of different communities constitute genuine disagreements, it becomes unclear whether moral relativists can rely on examples of unresolved moral disputes in order to motivate their view. ${ }^{9}$

\footnotetext{
7 The reasoning underlying the "simple deduction" creates a problem in the context of Wright's attempt to appeal to the criterion of "cognitive command"-roughly, whether disagreement in an area of discourse indicates mistake (Wright, 1992, 92f)-in order to distinguish between areas of discourse for which a realist account is appropriate and areas of discourse for which an anti-realist account is appropriate. Wright's discussion shows that there is a close connection between the idea that disagreement must imply mistake and the idea that a certain area of discourse is a matter of objective fact. Relativism about a given area of discourse is usually taken to presuppose that that area of discourse is not a matter of objective fact. This gives the relativist some leeway to deny an important presupposition underlying the challenge that I will explore in the next section.

8 While I have left open for the time being whether moral relativists are committed to Symmetry in the sense of Equal Validity, the assumption that disagreement always indicates mistake threatens to undermine any plausible version of Symmetry, including the one I will ultimately argue the moral relativist should subscribe to.

9 Because many moral relativists are semantic contextualists, they face an additional obstacle in accounting for disagreement, the so-called "problem of lost disagreement". If by uttering "Eating animals is morally wrong" A claims that eating animals is morally wrong according to set of moral standards $\mathrm{S}_{1}$ and by uttering "eating animals is not morally wrong" B claims that eating animals is not morally wrong according to set of moral standards $\mathrm{S}_{2}$, then the contents they express are not rationally incompatible. While their dispute intuitively seems to evince a genuine disagreement, this disagreement is "lost" on a
} 
The challenge disagreement poses for moral relativists thus takes the form of an apparent dilemma that relies on several assumptions about disagreement. While the first horn of the dilemma relies on the assumption that disagreement always indicates that a mistake has been made, the second horn relies on the assumption that whenever two people hold incompatible attitudes, they are in a state of disagreement. However, these assumptions can be disputed. In the next section, I will discuss three different strategies moral relativists have relied on to escape the dilemma and argue that they face severe limitations.

\section{Disagreement: Lost, Faultless, and Hybrid}

\subsection{Giving up Disagreement}

One way to react to the challenge disagreement poses for moral relativists is simply to accept that while the disputes that moral relativists appeal to in order to motivate their view seem to constitute genuine moral disagreements, in fact, they don't, and argue that the disputants' views are nevertheless incompatible. This strategy depends on denying the assumption that whenever two people hold incompatible attitudes, they are in a state of disagreement. Rovane and Velleman both pursue this strategy (Rovane, 2013, 30; Velleman, 2015, 2, 55). This allows them to avoid the dilemma stated above: They can argue that moral disputes between members of different communities do not constitute genuine disagreements (so Symmetry holds), yet their views are incompatible (so Exclusiveness holds). However, the required kind of incompatibility is not easy to specify in a coherent and plausible way. Rovane and Velleman give different explanations for why, although disputes between members of different communities cannot constitute genuine disagreements, the disputants' views are nevertheless incompatible. While according to Rovane, their views cannot be conjoined because they do not stand in any logical relations and are thus "normatively insulated" (Rovane, 2013, 113), Velleman argues that there remains a "practical disagreement" (Velleman, 2015, 76). Neither of these solutions is fully satisfactory. Rovane's version of the strategy requires substantive revisionary assumptions about logic that seem ad hoc in the context at hand and while Velleman hints at the possibility of understanding disagreement differently, he does not explore it. Given the definition of disagreement introduced above, a successful defense of this strategy would have to either locate conflict in something other than a rational incompatibility of (doxastic or non-doxastic) attitudes or explain why this sort of conflict is insufficient for disagreement. This seems difficult to achieve. Moreover, this solution

Footnote 9 (continued)

contextualist interpretation. Because the authors I focus on defend versions of moral group relativism, they commit to versions of "semantic group contextualism" that take the contextually salient set of moral standards to be shared by a community rather than accepted by the speaker alone. Group contextualism is sometimes seen as a solution to the problem of lost disagreement from the perspective of contextualism (see e.g. Silk, 2017, 212). However, while group contextualism solves the problem at the level of intragroup disagreement, the problem of lost disagreement returns at the level of inter-group disagreement. 
comes at a cost because disputes between members of different communities seem to indicate genuine disagreements. The strategy thus requires an "error theory" that explains why disputes between members of different communities seem to evince genuine disagreements and are treated as such, although they do not in fact constitute disagreements.

\subsection{Faultless Disagreement}

Another option for moral relativists to react to the challenge is to argue that while disputes between members of different communities $d o$ constitute genuine moral disagreements, this does not mean that one of the disputants must be mistaken. That is, they can argue that the relevant disagreement is "faultless". This strategy depends on rejecting the assumption that disagreement must always indicate that a mistake has been made. One way to render the notion of a faultless disagreement coherent is by adopting a relativist semantics for moral judgments. While according to semantic contextualism, the content of an utterance is relative to context, according to semantic relativism, the content remains un-relativized, but the truth-value is relative to context. Thus, according to a relativist semantics for moral judgments, if someone utters "Eating animals is morally wrong" what they are really expressing is that eating animals is morally wrong, but whether this is true or false is relative to some contextually salient set of moral standards $\mathrm{S}$, which is determined by the context of utterance, usually the set of moral standards accepted by the speaker. ${ }^{10}$ This makes it possible to account for faultless disagreement: if by uttering "Eating animals is morally wrong" A claims that eating animals is morally wrong and this is true relative to their set of standards or "perspective" and by uttering "Eating animals is not morally wrong" B claims that eating animals is not morally wrong and this is true relative to their perspective, then $\mathrm{A}$ and $\mathrm{B}$ disagree, yet their disagreement involves no mistake (cf. Kölbel, 2004, 70). ${ }^{11}$

Max Kölbel defends a version of moral group relativism that is based on a sophisticated form of semantic relativism (Kölbel, 2005). From the point of view of moral group relativists that commit to a contextualist semantics for moral judgments, adopting this strategy would require a revision of their semantic commitments. However, doing so would allow them to avoid the dilemma. They can argue that moral disputes between members of different communities constitute genuine

\footnotetext{
10 An alternative version of semantic relativism takes the relevant set of standards to be determined by the "context of assessment", in which an utterance is assessed (MacFarlane, 2014). However, the difference between these versions of semantic relativism do not matter for the purposes of my argument. While MacFarlane rejects the notion of a "faultless disagreement" as unhelpful, his view implies that disagreement is faultless in the sense I take to be relevant-in his terminology, that attitudes that are "doxastically non-cotenable" can both be "accurate" and not in violation of constitutive norms governing belief and assertion (MacFarlane, 2014, 133-36).

11 Other possibilities to render the notion of faultless disagreement coherent include adopting non-classical logics, such as intuitionism (Wright, 2001) or dialetheism (Odrowąż-Sypniewska, 2013). I will not consider these variants in any detail because they face severe difficulties (Wright, 2006, 48-50; Kölbel, 2004, 60-62; Priest, 2013, 94).
} 
disagreements based on a conflict in attitudes (so Exclusiveness holds): While A believes (and asserts) that eating animals is morally wrong, B believes (and asserts) that eating animals is not morally wrong. ${ }^{12}$ Yet, these disagreements are faultless because what A and B believe (and assert) is true relative to their respective perspectives (so Symmetry holds). Of course, there is a sense in which the incompatibility disappears when each belief (or assertion) is considered as true relative to the perspective of the speaker. While this does not undermine the point that adopting a relativist semantics allows the moral relativist to identify a conflict in attitudes, it has bearing on whether it allows the moral relativist to account for a pragmatic point of the dispute. If we assume that disputants are aware of the norms governing their assertions-according to which they ought to believe and assert a claim if it is true relative to their perspective-and that they aim at having true beliefs and making true assertions, it becomes unclear why they should bother engaging in the dispute. However, semantic relativists can provide additional considerations that explain why engaging in the dispute has a pragmatic point. Alternatively, they could settle for an "error theory" that explains why some disagreements, such as moral disagreements, seem to have a pragmatic point and disputants take them to have one, although-according to a relativist semantics-there is none.

In any case, I will not take issue with the claim that semantic relativists can account for disagreement here. Rather, I want to focus on a different but related consequence of this strategy. On an account of moral inter-group disagreement in terms of semantic relativism, these disagreements have no epistemic significance. This is because-as long as disputants say something that is true according to their own perspective-these disagreements are faultless. Finding oneself in a disagreement with someone who holds a different perspective thus provides no indication about whether one has committed a mistake relative to one's own standards. This is problematic because moral disagreements are often treated as having (at least some) epistemic significance-even if they occur across great spatial and temporal distance-and engaging in them can serve an important epistemological function. The strategy thus requires an "error theory" that explains why it would be a mistake to treat moral disagreements as having epistemic significance; yet accepting such an error theory would make one unable to account for the epistemically constructive role engaging in an argument about e.g. whether eating animals is morally wrong can play in processes of attitude-revision. ${ }^{13}$

\footnotetext{
12 This is often taken to be a main advantage of semantic relativism over semantic contextualism (see e.g. MacFarlane, 2014, Chapter 6).

13 On a semantic relativist view, disagreements thus have no epistemic significance because (given that each disputant is right about what is true relative to their set of standards) they are always faultless, in the sense that each disputant is believing (asserting) something that is true relative to their perspective. However, what about a different notion of mistake, according to which there might be something wrong with the perspectives endorsed by the disputants themselves? Appealing to such a notion of mistake would bring the semantic relativist strategy closer to the strategy I will ultimately argue for. I will discuss the implications of this strategy in detail in Sect. 4.
} 


\subsection{Hybrid-Expressivist Disagreement}

A third way to react to the challenge disagreement poses for moral relativists is to argue that while disputes between members of different communities do not constitute disagreements in terms of the doxastic attitudes expressed, they constitute disagreements in terms of the non-doxastic attitudes expressed. This requires adopting additional expressivist semantic commitments, according to which the function of moral judgments is not to make claims about how things are, but to express attitudes of the speaker. Combined with the contextualist semantic commitments moral relativists already undertake, this leads to a hybrid-expressivist view, on which moral judgments have both representational and non-representational functions. Harman and Wong have both suggested variants of this kind of solution. Wong introduces a distinction between conflict over what is true, which presupposes that disputants use moral expressions with the same meaning, and another kind of conflict that is "illocutionary and pragmatic and is made possible by the action-guiding functions of morality" (Wong, 2006, 77). He takes this to show that "noncognitivists' analyses of moral concepts are partly correct" (Wong, 2006, 72). In a similar vein, Harman explores what he calls a "quasi-absolutist" semantics, according to which moral relativists can use non-relativized moral expressions in a "quasi-absolutist" way to "express the speaker's attitude toward certain standards" (Harman, 1996, 35). He takes this to be a further development of emotivism (Harman, 1996, 34).

In order for this "hybrid-expressivist" strategy to avoid the dilemma, it has to be assumed that the non-doxastic attitudes expressed do not answer to unique standards of correctness. Otherwise, even conflict in non-doxastic attitudes would indicate that a mistake has been made. In other words, if the additional expressivist semantic commitments take a "quasi-realist" form that can account for the truth-functional behavior of moral discourse, even though the judgments themselves are not taken to be truth-apt, Wright's "simple deduction" could be reformulated in terms of nondoxastic attitudes (see also Kölbel, 2004, 65f). Therefore, the disagreement on the level of conflicting non-doxastic attitudes must be faultless. Thus, ultimately, this strategy also depends on rejecting the assumption that disagreement must always indicate that a mistake has been made. Adopting it allows the moral relativist to avoid the dilemma: They can argue that while moral disputes between members of different communities constitute genuine disagreements based on an incompatibility of non-doxastic attitudes (so Exclusiveness holds), these disagreements are faultless (so Symmetry holds).

Because any successful variant of this strategy has strong similarities to accounting for disagreement as faultless based on semantic relativism, its costs and benefits are similar as well. From the point of view of moral relativists that commit to a contextualist semantics of moral judgments, explaining disagreement in terms of hybridexpressivism requires adopting additional and controversial semantic commitments. While doing so would allow the moral relativist to identify a conflict in attitudes, as in the case of faultless disagreement based on semantic relativism, it is less clear whether it can vindicate a pragmatic point to the disagreement if disputants were fully informed. This is because, unless there are standards of correctness for attitudes, it is unclear whether it would make sense to engage in a disagreement at the 
level of those attitudes. At least more would have to be said to explain why engaging in this kind of disagreement has a point. Most importantly, because according to an explanation of moral inter-group disagreement in terms of hybrid-expressivism these disagreements are always faultless, it also implies that moral inter-group disagreements have no epistemic significance. This is problematic because it is in tension with ordinary attitudes towards moral disagreements and cannot account for the constructive role disagreement can play for attitude-revision. ${ }^{14}$

There are, thus, two main ways to respond to the challenge the phenomenon of moral inter-group disagreement poses for moral group relativists. The moral relativist can (i) either insist that moral disputes between members of different communities constitute genuine disagreements but deny that this means that at least one of them must be mistaken or (ii) give up the claim that moral disputes between members of different communities constitute genuine disagreements but deny that this means that their positions are compatible. While the former type of strategy manages to retain disagreement, but only at the cost of losing its epistemic significance, the latter gives up disagreement and has a hard time reconciling lack of disagreement with incompatibility between attitudes. In the next section, I will introduce an alternative strategy-accounting for moral inter-group disagreement in terms of what Plunkett and Sundell call "metalinguistic negotiation"-and argue that it has distinctive advantages.

\section{Moral Inter-Group Disagreement as Metalinguistic Negotiation}

In developing the notion of a "metalinguistic negotiation", Plunkett and Sundell draw on Chris Barker's idea of "metalinguistic usage" that can be illustrated by way of an example. The expression " $\mathrm{X}$ is tall" is usually used in order to communicate information about someone's height. Assuming a contextualist analysis of gradable adjectives, this is achieved by implicitly referring to a contextually salient standard (a threshold for being tall). However, as Barker has pointed out, in a situation in which $\mathrm{X}$ is nearby and in plain view, it is equally possible to use the expression " $\mathrm{X}$ is tall" in order to communicate information about the contextually salient threshold for being tall. This would amount to a metalinguistic use of " $\mathrm{X}$ is tall" that exploits common knowledge about someone's height in order to communicate something about the context (Barker, 2002, 1f). Drawing on this insight, Plunkett and Sundell consider what would happen if a dispute were to occur in the situation at hand. They argue that this dispute would center on the contextually salient threshold for being tall rather than X's height and would thus also be metalinguistic. They further distinguish cases in which there is a matter of fact about what the relevant contextually salient standard is and cases in which the dispute centers on what the standard ought

\footnotetext{
${ }^{14}$ Like the semantic relativist, the hybrid-expressivist could in principle appeal to a different notion of mistake that consists in endorsing the wrong set of standards. This would make this strategy similar to the strategy I will argue for and discuss below.
} 
to be. They call the latter kind of cases "metalinguistic negotiations" (Plunkett \& Sundell, 2013, 3).

Adopting this notion of disagreement allows the moral relativist to account for moral inter-group disagreement while remaining committed to semantic contextualism for moral judgments. On a contextualist semantics for moral judgments, by uttering "Eating animals is morally wrong" A claims that eating animals is morally wrong according to set of moral standards $S_{1}$ and by uttering "Eating animals is not morally wrong" B claims that eating animals is not morally wrong according to set of moral standards $S_{2}$. The contents they literally express are thus rationally compatible. Nevertheless, the dispute constitutes a genuine disagreement because A and $\mathrm{B}$ are using their utterances metalinguistically in order to pragmatically advocate for their respective parameter settings. While A commits to and communicates the content that "morally wrong" should be used with reference to set of standards $S_{1}$ (according to which eating animals is morally wrong), B commits to and communicates the content that "morally wrong" should be used with reference to set of moral standards $S_{2}$ (according to which eating animals is not morally wrong). While this kind of disagreement could be carried out explicitly, it can also be carried out implicitly, via the mechanism of metalinguistic negotiation.

Explaining disagreement in terms of metalinguistic negotiation thus allows the moral relativist to identify a conflict in attitudes: namely, the disputants have inconsistent views on how the expression "morally wrong" should be used. ${ }^{15}$ In addition, adopting this strategy allows the moral relativist to specify a pragmatic point of engaging in the dispute. Plunkett and Sundell emphasize that metalinguistic negotiations constitute disagreements "worth having" because how we use words matters (Plunkett \& Sundell, 2013, 22-24). This can be illustrated with respect to the examples Plunkett and Sundell provide, such as disputes about what should count as "spicy" when cooking together, what should count as "cold" in a shared office, what should count as "rich" when determining a tax-base (Plunkett \& Sundell, 2013, 14f) and, perhaps most strikingly, whether to use the term "torture" in such a way that it includes waterboarding (Plunkett \& Sundell, 2013, 19f). ${ }^{16}$ These cases show that metalinguistic negotiations can be closely connected to collective decision-making regarding important normative issues. This is because they concern the use of expressions that play important "functional roles". As Plunkett and Sundell put it, metalinguistic negotiations involving moral expressions constitute disagreements worth having because moral expressions "play a functional role that concerns matters of how we navigate our decisions about how to treat others, what to hold each

\footnotetext{
15 This makes it possible to account for disagreement (as a state) also in cases where there is no shared context, such as moral inter-group disagreement across great temporal and spatial distance.

16 The range of examples shows that Plunkett and Sundell develop metalinguistic negotiation not only regarding context-sensitive expressions that are used with respect to different parameters but also regarding terms that are paired with different concepts. Accounting for moral inter-group disagreement in terms of metalinguistic negotiation is thus available to moral relativists that commit to a version of contextualism in the framework of formal semantics as well as to those that commit to semantic contextualism in the broad sense that moral expressions have different meanings in different contexts.
} 
other responsible for doing, and how to live more generally" (Plunkett \& Sundell, 2013, 20). ${ }^{17}$

While disputants could thus see a point in engaging in a dispute involving moral expressions if they were aware that it constitutes a metalinguistic negotiation, this does not mean that they are likely to accept this explanation. In fact, there is reason to assume that speakers who engage in a moral dispute would resist a characterization of their exchange as being about language. One might thus object that explaining moral inter-group disagreement in terms of metalinguistic negotiation mischaracterizes moral disagreements as being about language and comes at the cost of attributing a kind of "speaker error" concerning what moral disagreements are, in fact, about (cf. Plunkett \& Sundell, 2019, 9). However, to explain moral intergroup disagreement in terms of metalinguistic negotiation, moral relativists need not claim that all moral disagreement is about language, but only that a special kind that occurs between members of different communities is. ${ }^{18}$ In these cases of disagreement, speakers use context-sensitive moral expressions with respect to different standards. It is implausible to assume that, even if this was the right view, speakers would be aware of this mechanism or could be easily made aware of it. As Plunkett and Sundell argue, even if speakers do turn out to have views of such intricate linguistic matters-which seems unlikely-and these views were to contradict an explanation in terms of metalinguistic negotiation, this would only commit the proponent of metalinguistic negotiation to the claim that speakers are wrong about "folk-linguistics", but not about how to use language. This kind of attribution of speaker error is less problematic as it does not serve to isolate a theory from potentially recalcitrant data about language use (Plunkett \& Sundell, 2019, 14-19). Moreover, speaker's reluctance to think of these disputes as metalinguistic can be accounted for (cf. Plunkett \& Sundell, 2019, 21f). While disagreements that turn out to be "merely verbal" are often taken to be unimportant and not worth pursuing, moral disagreements are often taken very seriously. However, as Plunkett and Sundell's example of how to use the term "torture" elucidates, many linguistic disagreements are closely connected to practical matters and to disagreements that are not about language.

\footnotetext{
17 As Plunkett and Sundell point out, this emphasis on the practical significance of how we use words closely connects their view of disagreement to "conceptual ethics" (see Burgess and Plunkett, 2013a; 2013b). As will become clear below, the fact that they refer to the "functional role" of terms to elucidate the practical significance of how we use words will play an important role for my argument. A similar approach to conceptual ethics (or "conceptual engineering") that also draws on the idea that words (or concepts) play a functional role is developed by Amie Thomasson, who attributes this type of view to Sally Haslanger (Haslanger, 2000; Thomasson, 2020). Herman Cappelen develops a critique of this notion of a functional role, which Thomasson engages with, but which is beyond the scope of this paper (Cappelen, 2018).

${ }^{18}$ But is there also a positive reason why moral inter-group disagreements should be interpreted as metalinguistic negotiations? As Delia Belleri points out, considerations of charity can play an important role in arguing that a given exchange should be regarded as a metalinguistic negotiation (Belleri, 2020). From the point of view of a moral relativist committed to semantic contextualism, considerations of charity support interpreting moral inter-group disagreements as metalinguistic negotiations because otherwise the moral relativist would have to understand the disputants as talking past each other or (if they adopted one of the accounts of disagreement I discuss in Sect. 3) as engaging in a dispute with no clear pragmatic point.
} 
Therefore, metalinguistic negotiations can be both about language and about important normative issues.

Another worry associated with the pragmatic point of engaging in metalinguistic negotiation is that it might seem to be in tension with central tenets of moral relativism. This is because the notion of metalinguistic negotiation seems to presuppose that disagreements are worth having because there is a requirement of practical coordination. This is suggested by the examples Plunkett and Sundell rely on, such as cooking chili together and heating a shared office, but also by the term "negotiation" itself. One might thus object that, while moral relativism might be compatible with some degree of coordination between communities and overlap between different moral systems, it is certainly incompatible with a requirement of universal convergence. However, although this is in fact suggested by the majority of the cases Plunkett and Sundell discuss, as Sundell also notes, coordination is not the only pragmatic point engaging in a metalinguistic negotiation can have (Sundell, 2017, 91). Alexander Davies argues that "identity display" constitutes another important motivation underlying metalinguistic negotiations. This is because how we use words can be a "marker" of social identity "and it is important to us that our social identities are seen and understood" (Davies, 2020, 2). ${ }^{19}$ The more general upshot is that engaging in a metalinguistic negotiation can have different points in different contexts. One point of engaging in moral disagreement is to try to learn from the other disputant even though coordination is not required. Explaining moral intergroup disagreement in terms of metalinguistic negotiation, thus, allows the moral relativist to specify a pragmatic point of engaging in these disputes that is compatible with moral relativism.

At first sight, it might seem that-just as explaining disagreement in terms of semantic relativism or hybrid-expressivism-explaining moral inter-group disagreement in terms of metalinguistic negotiation leads to a view on which moral intergroup disagreement is faultless. This is because according to this explanation of moral inter-group disagreement, both disputants literally express something true. However, this is not the only, let alone the most interesting notion of faultlessness in the context of a contextualist semantics for moral judgments. As Plunkett and Sundell emphasize, metalinguistic negotiations have a point because there is a substantive question about which way of using a given expression is better in the context at hand. This is because the functional role expressions play provides a standard to assess a given use of a term as better or worse. Considering the example of someone who, while baking cupcakes, uses "tasty" with reference to a standard that is highly unsuitable given the functional role of this term, Sundell points out that such a person makes a mistake, even though they manage to express a true proposition (Sundell, 2016, 812). Thus, in contrast to other solutions that retain the claim that moral disputes between members of different communities constitute genuine disagreements, explaining moral inter-group disagreement as metalinguistic negotiation

\footnotetext{
19 This kind of reasoning also helps to rebut another objection against accounts of disagreements in terms of metalinguistic negotiation in general: that in some of the target cases of disputes that seem to evince genuine disagreements no question of practical coordination is at stake (Zeman, 2017, 67).
} 
does not imply that this kind of disagreement is always faultless. This is because it appeals to a different notion of mistake, according to which someone can be at fault for using a context-sensitive expression with respect to a standard that is unsuitable given the functional role of the term. It does, however, vindicate the possibility of faultless disagreement as a special case. Disagreement is faultless just in case the disputants use context-sensitive expressions with respect to standards that are equally suitable given the functional role of the relevant expression. ${ }^{20}$

Because explaining moral inter-group disagreement in terms of metalinguisticnegotiation leads to a view on which moral inter-group disagreement can but need not be faultless, to see how it allows the moral relativist to avoid the dilemma, two different cases need to be considered. First, consider a case of moral inter-group disagreement in which the disputants use a moral expression with respect to moral standards that allow this term to fulfill its functional role equally well. In this case, the disagreement will be faultless in the relevant sense. Note that the disagreement will also be faultless in the sense that both disputants literally express something true; however, that is not the sense of faultlessness that is salient in the context at hand. Explaining the dispute in terms of metalinguistic negotiation allows the moral relativist to avoid the dilemma: They can argue that it evinces a genuine moral disagreement based on rationally incompatible attitudes (so Exclusiveness holds), yet this disagreement is faultless (so Symmetry holds). Next, consider a case of moral inter-group disagreement in which one disputant uses a moral expression with respect to moral standards that allow this term to fulfill its functional role better than when it is used with respect to the standards the other disputant is appealing to. In this case, the disagreement will still be faultless in the sense that both disputants literally express something true. However, as noted above, this is not the sense of faultlessness relevant in the context at hand and it is not sufficient to vindicate Symmetry. This has consequences for the question whether this solution is compatible with the motivation underlying moral relativism.

The claim that the functional role of moral expressions provides a standard to assess a given use that refers to a set of moral standards as better or worse than another one implies that moral systems themselves can be assessed as better or worse. Moral relativists who adopt this strategy, thus, commit to Symmetry in the sense of Equal Validity only as a special case: moral systems are equally valid in case they fulfill the functional role of systems of moral norms equally well. Although the idea that moral systems fulfill a common function might be taken to be

\footnotetext{
${ }^{20}$ While disputants might also disagree about which of two competing uses allows a term to better fulfill its functional role as well as about what this functional role is, according to this view, these disagreements need not and will often not be faultless. A parallel story can be given about faultless disagreement with respect to metalinguistic negotiations that do not involve context-sensitive expressions used with respect to different parameters, but terms used to denote different concepts. Plunkett and Sundell discuss the case of disputants disagreeing about whether "Waterboarding is torture", where one disputant is assuming the United Nations definition of torture, according to which the statement is true, whereas the other disputant is using the U.S. Department of Justice definition, according to which it is false. They emphasize that, although both disputants manage to literally express a true proposition and are strictly speaking talking past each other, "there is a substantive question about which definition is better" (Plunkett and Sundell, 2013, 19).
} 
in tension with moral relativism, in fact, some versions of moral relativism-such as the views defended by Velleman and Wong-already commit to this idea (Velleman, 2015, 97; Wong, 2006, 39f). ${ }^{21}$ Because it does allow for the possibility of faultless disagreement, explaining moral inter-group disagreement in terms of metalinguistic negotiation is compatible with the central motivation underlying moral relativism: the idea that different moral systems can require incompatible courses of action, yet both be genuinely valid in their respective context. However, while explaining moral inter-group disagreement in terms of metalinguistic negotiation goes well with "functionalist" versions of moral relativism, it might indeed introduce an element of tension into other versions.

The strategy of explaining moral inter-group disagreement in terms of metalinguistic negotiation thus rejects the assumption that disagreement must always indicate that a mistake has been made, which underlies the dilemma, but accepts that disagreement can sometimes indicate that a mistake has been made. Because, on this view, disagreement can but need not indicate that a mistake has been made, it implies that the epistemic significance of moral inter-group disagreement is nuanced. Moral inter-group disagreements give us reason to reconsider our view because they can be due to the fact that a mistake has been made (in the sense that a moral expression such as "morally right" is used with respect to a standard that is worse than a rival one given the functional role of moral expressions). They, thus, have more epistemic significance than disagreements that are always faultless such as e.g. disagreements about whether licorice is tasty. At the same time, the account allows for the possibility that moral inter-group disagreements can be faultless. They thus have less epistemic significance than disagreements that are never faultless such as moral inter-group disagreements (on a group-relativist view) or disagreements about the outcome of a calculation.

Like the strategies discussed above-giving up disagreement and explaining disagreement in terms of semantic relativism or hybrid-expressivism-explaining disagreement in terms of metalinguistic negotiation allows the moral relativist to avoid the dilemma. However, unlike these other strategies it manages to do so without giving up the view that moral disputes between members of different communities can constitute genuine moral disagreements that are epistemically significant. The main advantage of this strategy is thus that it leads to a nuanced understanding of the epistemic significance of moral inter-group disagreements. However, both proposals that vindicate genuine moral inter-group disagreement-explaining disagreement in terms of semantic relativism and hybrid-expressivism-could be further developed to incorporate a notion of disagreement as metalinguistic negotiation in addition to their semantic commitments. All it takes to do so is a distinction between what is

\footnotetext{
${ }^{21}$ They do so for reasons that are independent of the moral relativist's problem with disagreement. In order to maintain that different moral systems conflict, the moral relativist must claim that they license different verdicts about the same topic. Moreover, as Velleman points out, in order not to collapse into nihilism-the view that no set of moral norms has the validity we usually take moral norms to havemoral relativists have to give an account of what makes different sets of moral norms valid in their context (Velleman 2015, 76). Arguing that moral systems serve a certain function is one way to meet these requirements.
} 
literally expressed and what is communicated. In this case, these proposals would be very similar to the view I am suggesting. ${ }^{22}$ The only remaining difference would be that, from the point of view of moral relativists already committed to semantic contextualism for moral judgments, these strategies would require adopting additional semantic commitments. While there might be independent reasons to undertake semantic commitments of a relativist or hybrid-expressivist kind, they would no longer be necessary to account for disagreement.

Explaining moral inter-group disagreements in terms of metalinguistic negotiation thus allows the moral relativist to explain (i) why moral disputes between members of different communities constitute genuine disagreements, (ii) why engaging in these disputes has a point, and (iii) why moral inter-group disagreements do have at least some epistemic significance. In the next section, I will discuss an objection to the assumption that moral disagreement between members of different communities are in fact taken to have epistemic significance.

\section{Are Moral Inter-Group Disagreements Taken to Have Epistemic Significance?}

The assumption that moral inter-group disagreements are in fact treated as having epistemic significance plays a crucial role for my argument. A challenge to this assumption comes from experimental philosophy. Sarkissian et al. have conducted a series of studies, in which subjects (all of which are students) are confronted with examples of severe moral transgressions. They are told that one of their classmates thinks that this act is morally wrong, but someone else disagrees with this. Then they are asked to indicate their agreement with the statement "Since your classmate and [the dissenter] have different judgments about this case, at least one of them must be wrong" on a scale from 1 ("disagree") to 7 ("agree") (Sarkissian et al., 2011, 487). Crucially, the study involves a variation in condition. Sometimes subjects are told that the dissenter is someone close to them (another classmate named "Sam"), other times they are told that it is someone from a very different culture (a member of the isolated tribe of the "Mamilons" that have preserved a traditional warrior culture) or even an extraterrestrial (a "Pentar", whose main goal is to increase the total number of equilateral pentagons in the universe) (Sarkissian et al., 2011, 487f).

\footnotetext{
22 Adopting a different broadly pragmatic account of disagreement - such as e.g. Stephen Finlay's “quasi-expressivism” (Finlay, 2014), Justin Khoo and Joshua Knobe's account of disagreement in terms of incompatible proposals to update the conversational context (Khoo and Knobe, 2016), or accounts of disagreement referring to presuppositions of "commonality" or "superiority" (Zeman, 2017)-would not automatically lead to the same advantages. This is because the implication that the epistemic significance of moral inter-group disagreement is nuanced (because it can but need not be faultless) depends on reference to the functional role of expressions and is thus unique to Plunkett and Sundell's account of disagreement in terms of metalinguistic negotiation. Of course, other pragmatic accounts of disagreement could in principle be further developed such that they lead to a similar view of faultlessness and epistemic significance.
} 
The study finds that the intuition that disagreement indicates mistake is stronger when subjects are told that the dissenter is someone from their own environment and weaker when they are told it is someone from a very different context. ${ }^{23}$ This result is interpreted as showing that-in contrast to what prior experiments seemed to show-folk opinion does not vindicate moral objectivity, but instead is in line with moral relativism, at least when subjects are confronted with cases in which a judge comes from a very different context. ${ }^{24}$ These results seem to undermine the claim that moral disagreements are taken to have epistemic significance even across radically different contexts.

In response to this challenge, I want to suggest a different interpretation of the study, which better fits the data. The datapoints show that while assent to the statement that disagreement implies mistake is significantly lower in cases in which the dissenter is from a very different context, it is still not low enough to unambiguously indicate disagreement with the claim that disagreement indicates that a mistake has been made and agreement with its opposite-that disagreement is faultless. Instead, the answers are somewhere around the midpoint between 1 ("disagree") and 7 ("agree"). ${ }^{25}$ Rather than undermining the claim that moral disagreements across different contexts are taken to have epistemic significance, the details of the results, thus, support the view that the epistemic significance of moral inter-group disagreement is nuanced. ${ }^{26}$ According to an account of moral inter-group disagreement in

\footnotetext{
23 This proved to be the case when different subjects were provided with different conditions as well as when the same subjects were provided with different conditions side-by-side (Sarkissian et al., 2011, 491f).

24 The topic of the study is thus moral objectivity, rather than moral disagreement. The study relies on intuitions about whether disagreement indicates mistake as an indicator of intuitions about objectivity. This, again, shows how close the connection between objectivity and the claim that disagreement must indicate mistake is sometimes taken to be. As a study about objectivity and relativism it faces the worry that even though subjects might have an intuition about disagreement, they might lack one about moral objectivity (Pölzler and Wright, 2019, 8). However, it provides more reliable data about subjects' intuitions on whether disagreement implies mistake because this is what it directly tests for.

25 In the first study, which assigned different conditions to different subjects, the mean of answers for the other-culture condition was slightly above the midpoint of $4(\mathrm{M}=4.4, \mathrm{SD}=2.05)$ and the mean of answers for the extraterrestrial condition was slightly below $(\mathrm{M}=3.2, \mathrm{SD}=2.28)$ (Sarkissian et al., 2011, 488f). The same study in a different setting led to similar results, but no exact numbers are given (Sarkissian et al., 2011, 490). In another study, in which subjects were presented with different conditions side-by-side, the mean of answers for the other-culture condition was slightly lower $(\mathrm{M}=4.3, \mathrm{SD}=2.11)$ and the mean of answers for the extraterrestrial condition was slightly higher $(\mathrm{M}=3.7, \mathrm{SD}=1.97)$ (Sarkissian et al., 2011, 491). Further variations of the study dealt with the identity of the actor rather than the judge, comparison to non-moral cases and the exact interpretation of the phrase that "at least one of them must be wrong" (Sarkissian et al., 2011, 492-500). The results of these variants were not in tension with the results of the first set of studies.

26 In particular, the study that compared intuitions for moral disagreement with intuitions about disagreements about non-moral facts showed that disagreements about facts are taken to have more epistemic significance (Sarkissian et al., 2011, 495-97). More generally, because it entails that the epistemic significance of disagreements comes in degrees and differs for different domains, accounting for moral inter-group disagreement in terms of metalinguistic negotiation is in line with the view that the "folk" are "metaethical pluralists", in the sense that they have different intuitions about objectivity for different domains, which seems to be a lesson of experimental research (Pölzler and Wright, 2019).
} 
terms of metalinguistic negotiation, this is explained by the fact that it can but need not indicate that a mistake has been made. ${ }^{27}$

\section{Conclusion}

In addition to the claim that it makes it impossible to explain moral disagreement between members of different communities, a longstanding objection to moral relativism is that it makes constructive discourse between different moral traditions impossible (Wong, 2006, 76). Both of these worries go back to the idea that moral disagreements are ordinarily taken to have epistemic significance-they give us reason to reconsider our position and engage in argument-that threatens to be lost on a relativist view of morality. While some moral relativists are happy to accept that there is no genuine moral disagreement between members of different communities and engaging in apparent conflicts is pointless, others have tried to accommodate the idea that there can be real disagreement between distant points of view that is worth pursuing within the boundaries of moral relativism. However, so far, these attempts have fallen short of recovering the epistemic significance of moral disagreement. I have argued that a novel approach-explaining moral inter-group disagreement as metalinguistic negotiation-can solve this problem.

I have started by explaining why accounting for moral disagreement between members of different communities constitutes a challenge to the coherence of moral relativism. Then, I have discussed three different strategies moral relativists have pursued to meet this challenge: giving up disagreement, arguing for faultless disagreement based on semantic relativism, and explaining disagreement in terms of hybrid-expressivism. I have argued that all of these solutions come at a cost because they either give up disagreement or vindicate disagreement only without epistemic significance. Subsequently, I have argued that moral relativists are better off accounting for moral inter-group disagreement in terms of metalinguistic negotiation because this leads to a view of the epistemic significance of these disagreements as nuanced. Finally, I have addressed an objection to the assumption that moral disagreements between members of different communities are in fact taken to have epistemic significance. As I have pointed out, because it leads to a view on which different moral systems can, but need not be "equally valid", the strategy of explaining moral inter-group disagreement in terms of metalinguistic negotiation is only compatible with some versions of moral relativism, such as e.g. "functionalist" versions. However, because, in presenting an attractive picture of the epistemic significance of moral inter-group disagreements, this strategy allows the moral relativist to avoid

\footnotetext{
27 Another possible interpretation of the data would be that subjects have no clear intuitions on the subject matter (cf. Pölzler and Wright, 2019, 8). If this is the case, it might be due to the unrealistic descriptions of judges in the other-culture and extraterrestrial condition. In this case, the results of the study would not support an account of moral inter-group disagreement in terms of metalinguistic negotiation but could not ground an objection to the view either.
} 
some longstanding objections, this provides a pro tanto argument in favor of these versions of moral relativism.

Acknowledgments For helpful comments on earlier versions of this paper, I would like to thank Delia Belleri, Alexander Davies, Vera Flocke, Daniel Sharp, Dan Zeman, members of the audience at the 2019 Salzburg Conference for Young Analytic Philosophy (SOPhiA), as well as three anonymous referees.

Funding Open Access funding enabled and organized by Projekt DEAL.

Open Access This article is licensed under a Creative Commons Attribution 4.0 International License, which permits use, sharing, adaptation, distribution and reproduction in any medium or format, as long as you give appropriate credit to the original author(s) and the source, provide a link to the Creative Commons licence, and indicate if changes were made. The images or other third party material in this article are included in the article's Creative Commons licence, unless indicated otherwise in a credit line to the material. If material is not included in the article's Creative Commons licence and your intended use is not permitted by statutory regulation or exceeds the permitted use, you will need to obtain permission directly from the copyright holder. To view a copy of this licence, visit http://creativecommons.org/licen ses/by/4.0\%.

\section{References}

Barker, C. (2002). The dynamics of vagueness. Linguistics and Philosophy, 25(1), 1-36

Belleri, D. (2014). Disagreement and dispute. Philosophia, 42(2), 289-307

Belleri, D. (2020). Ontological disputes and the phenomenon of metalinguistic negotiation: Charting the territory. Philosophy Compass, 15(7), 1-11

Björnsson, G., \& Finlay, S. (2010). Metaethical contextualism defended. Ethics, 121(1), 7-36

Burgess, A., \& Plunkett, D. (2013a). Conceptual Ethics I. Philosophy Compass, 8(12), 1091-1101

Burgess, A., \& Plunkett, D. (2013b). Conceptual Ethics II. Philosophy Compass, 8(12), 1102-1110

Cappelen, H., \& Hawthorne, J. (2009). Relativism and Monadic Truth. Oxford University Press.

Cappelen, H. (2018). Fixing Language: An Essay on Conceptual Engineering. Oxford University Press.

Carter, J. A. (2014). Disagreement, relativism and doxastic revision. Erkenntnis, 79, 155-172

Christensen, D. (2007). Epistemology of disagreement: The good news. The Philosophical Review, $116(2), 187-217$

Davies, A. (2020). Identity display: Another motive for metalinguistic disagreement. Inquiry.

Finlay, S. (2014). Confusion of Tongues: A Theory of Normative Language. Oxford University Press.

Fogelin, R. (2005). the logic of deep disagreements. Informal Logic, 25(1), 3-11

Francén, R. (2010). No deep disagreement for new relativists. Philosophical Studies, 151(1), 19-37

Harman, G. (1975). Moral relativism defended. The Philosophical Review, 84(1), 3-22

Harman, G. (1996). Moral Relativism. In G. Harman \& J. J. Thomson (Eds.), Moral Relativism and Moral Objectivity. (pp. 1-64). Blackwell.

Haslanger, S. (2000). Gender and race: (What) are they? (What) do we want them to be? Noûs, 34(1), $31-55$

Khoo, J., \& Knobe, J. (2016). Moral disagreement and moral semantics: Moral disagreement and moral semantics. Noûs, 52(1), 109-143

Kinzel, K., \& Kusch, M. (2018). De-idealizing disagreement, rethinking relativism. International Journal of Philosophical Studies, 26(1), 40-71

Kölbel, M. (2004). Faultless disagreement. Proceedings of the Aristotelian Society, 104(1), 53-73

Kölbel, M. (2005). Moral Relativism. In D. Westerstahl \& T. Tännsjö (Eds.), Lectures on Relativism. (pp. 51-72). Göteburg University.

Kusch, M. (2016a). Relativism in Feyerabend's later writings. Studies in History and Philosophy of Science Part A, 57, 106-113

Kusch, M. (2016b). Wittgenstein's On Certainty and Relativism. (In S. Rinofner-Kreidl \& H. A. Wiltsche (Eds.), Analytic and Continental Philosophy: Methods and Perspectives. Proceedings of the 37th International Wittgenstein Symposium (pp. 29-46). De Gruyter. 
Lavorerio, V. (2018). Do deep disagreements motivate relativism? Topoi.

MacFarlane, J. (2014). Assessment Sensitivity: Relative Truth and Its Applications. Oxford University Press.

Odrowąż-Sypniewska, J. (2013). Paraconsistent vs. Contextual solutions to sorites. Polish Journal of Philosophy, 7(2), 21-36

Plunkett, D., \& Sundell, T. (2013). Disagreement and the semantics of normative and evaluative terms. Philosopher's Imprint, 13(23), 1-37

Plunkett, D. \& Sundell, T. (2019). Metalinguistic negotiation and speaker error. Inquiry, 64(1-2), $142-167$.

Pölzler, T., \& Wright, J. C. (2019). Empirical research on folk moral objectivism. Philosophy Compass, 14(5), 1-15

Priest, G. (2013). Replies. Polish Journal of Philosophy, 7(2), 93-108

Rovane, C. (2013). The Metaphysics and Ethics of Relativism. Harvard University Press.

Sarkissian, H., Park, J., Tien, D., Wright, J. C., \& Knobe, J. (2011). Folk Moral Relativism. Mind \& Language, 26(4), 482-505

Silk, A. (2017). Normative Language in Context. In R. Shafer-Landau (Ed.), Oxford Studies in Metaethics. (Vol. 12, pp. 206-243). Oxford University Press.

Silk, A. (2018). MetaethicalContextualism. In T. C. McPherson \& D. Plunkett (Eds.), The Routledge Handbook of Metaethics. (pp. 102-118). Routledge.

Stojanovic, I. (2018). Metaethical Relativism. In T. C. McPherson \& D. Plunkett (Eds.), The Routledge Handbook of Metaethics. (pp. 119-132). Routledge.

Sundell, T. (2016). The tasty, the bold, and the beautiful. Inquiry, 59(6), 793-818

Sundell, T. (2017). Aesthetic Negotiation. In J. O. Young (Ed.), The Semantics of Aesthetic Judgements. (pp. 82-105). Oxford University Press.

Thomasson, A. L. (2020). A Pragmatic Method for Normative Conceptual Work. In A. Burgess, H. Cappelen, \& D. Plunkett (Eds.), Conceptual Engineering and Conceptual Ethics. (pp. 435-458). Oxford University Press.

Velleman, J. D. (2015). Foundations for Moral Relativism. Second. (Expanded). Open Book Publishers.

Wong, D. B. (2006). Natural Moralities: A Defense of Pluralistic Relativism. Oxford University Press.

Wright, C. (1992). Truth and Objectivity. Harvard University Press.

Wright, C. (2001). On being in a quandary. Relativism Vagueness Logical Revisionism. Mind, 110(437), 45-98

Wright, C. (2006). Intuitionism, Realism, Relativism and Rhubarb. In P. Greenough \& M. P. Lynch (Eds.), Truth and Realism. (pp. 38-60). Oxford University Press.

Wright, C. (2012). Replies Part III: Truth, Objectivity, Realism, and Relativism. In A. Coliva (Ed.), Mind, Meaning, and Knowledge: Themes from the Philosophy of Crispin Wright. (pp. 418-450). Oxford University Press.

Zeman, D. (2017). Contextualist answers to the challenge from disagreement. Phenomenology and Mind, $12,62-73$

Publisher's Note Springer Nature remains neutral with regard to jurisdictional claims in published maps and institutional affiliations. 